\title{
Physician' attitudes to growth hormone replacement therapy in adults following pituitary surgery: Results of an online survey
}

\author{
Aishah Ekhzaimy, Salem A. Beshyah ${ }^{1,2}$, Khaled M. Al Dahmani3,4, Mussa H. AlMalki5,6
}

Department of Medicine, Endocrinology Division, King Saud University, King Saud University Medical City, Riyadh, Saudi Arabia, ${ }^{1}$ Department of Endocrinology, Mediclinic Airport Road Hospital, Abu Dhabi, United Arab Emirates, ${ }^{2}$ Department of Medicine, Dubai Medical College, Dubai, United Arab Emirates, ${ }^{3}$ Department of Medicine, United Arab Emirates University, United Arab Emirates, ${ }^{4}$ Division of Endocrinology, Tawam Hospital, Al Ain, United Arab Emirates, ${ }^{5}$ Obesity, Endocrine and Metabolism Centre, King Fahad Medical City, Riyadh, Saudi Arabia, ${ }^{6}$ College of Medicine, King Fahad Medical City, King Saud bin Abdul Aziz University for Health Sciences, Riyadh, Saudi Arabia

\begin{tabular}{|c|}
\hline Access this article online \\
\hline Website: www.avicennajmed.com \\
\hline DOI: 10.4103/ajm.ajm_46_20 \\
\hline Quick Response Code: \\
\hline
\end{tabular}

\begin{abstract}
Objective: The aim of this study was to evaluate physician attitudes and practices in the management of adult growth hormone deficiency (GHD) following pituitary surgery. Materials and Methods: An online questionnaire survey was sent to a sample group of physicians. Results: A total of 131 respondents provided usable responses. More than three quarters were senior physicians, with most practicing in tertiary care centers $(73 \%)$. Four-fifths of the respondents see at least 1 to 5 patients with GHD following pituitary surgery per year. Seventyfour percent acknowledge the benefit in principle of growth hormone replacement therapy (GHRT) for patients with GHD after pituitary surgery. Most respondents (84\%) would only consider GHRT for symptomatic patients. However, $16 \%$ stated that patients with GHD after pituitary surgery generally suffer from the side effects of GHRT. Forty-four percent said that the serum insulinlike growth factor-1 (IGF-1) level is the best screening test for assessing GHD after pituitary surgery but $57 \%$ of the respondents would use IGF-I levels, and $29 \%$ the insulin tolerance test (ITT), in patients with a documented deficiency in three pituitary axes. The main barriers to long-term GHRT use were that it requires injections $(67 \%)$, and is costly with limited supply $(61 \%)$. Other reasons not to use GHRT include an absence of GHD symptoms and apparent GHT ineffectiveness $(44 \%)$, physician lack of familiarity with the medication $(40 \%)$, and lack of adherence to available guidelines (38\%). Conclusion: This survey addressed physician attitudes and practices in recognizing and treating GHD in adult's post-pituitary surgery. Regional guidelines must be developed to help address/tackle these issues and assist physicians in understanding and treating this condition.
\end{abstract}

Key words: Adult growth hormone deficiency, growth hormone, insulin-like growth factor-1

\section{INTRODUCTION}

Growth hormone deficiency (GHD) syndrome in adults was not an accepted clinical condition until two decades ago when Cuneo and colleagues coined its name for the first time. ${ }^{[1]}$ Adults with GHD suffer changes in body composition, impaired quality of life (QoL)/psychological well-being, and increased cardiovascular disease risk. ${ }^{[1-4]}$ Epidemiological

Address for correspondence: Mussa $\mathrm{H}$. AlMalki,

Obesity, Endocrine and Meta-bolism Centre, King Fahad Medical City, Riyadh, Saudi Arabia.

E-mail:m2malki@yahoo.com studies in untreated adult patients with GHD confirmed high mortality due to cardiovascular disease. ${ }^{[2,5,6]}$ Many experts

This is an open access journal, and articles are distributed under the terms of the Creative Commons Attribution-NonCommercial-ShareAlike 4.0 License, which allows others to remix, tweak, and build upon the work non-commercially, as long as appropriate credit is given and the new creations are licensed under the identical terms.

For reprints contact: reprints@ medknow.com

Cite this article as: Ekhzaimy A, Beshyah SA, Al Dahmani KM, AIMalki $\mathrm{MH}$. Physician' attitudes to growth hormone replacement therapy in adults following pituitary surgery: Results of an online survey. Avicenna J Med 2020;10:215-22. 
and several professional organizations recognize adult GHD syndrome and have issued specific recommendations for its assessment and management on its own or in the context of adult hypopituitarism. ${ }^{[7,8]}$

GHD is by far the most frequent and earliest hormonal deficiency in adult patients with hypopituitarism resulting from pituitary tumors or their management. ${ }^{[6,7]}$ Several studies have shown that GHRT yields significant benefits by improving body composition and lipid metabolism, promoting a better cardiovascular risk profile, exercise performance, and QoL. ${ }^{[8-12]}$ Although the therapeutic clinical effects of GHRT are beneficial, there have been some concerns about the risk of tumor recurrence or growth, particularly in patients with previous or residual pituitary tumors. Although GHRT is contraindicated in patients with a known active malignancy, the safety data of GH replacement in GHD patients with a history of pituitary tumors were not associated with increased pituitary tumor recurrence in most studies focusing on radiation therapy patients. ${ }^{[13-16]}$ Furthermore, no increased risk of tumor recurrence was associated with GH replacement in patients treated only with surgery. ${ }^{[13]}$ Finally, data on the safety of GHRT with untreated pituitary adenomas are very limited. ${ }^{[12]}$

GHRT is endorsed as a valid treatment by different national and international guidelines. However, there are major international differences in using of GHRT for GHD after pituitary surgery. ${ }^{[17]}$ In this context, physician perceptions are drivers of clinical practice but GHRT use has not been widely ascertained. ${ }^{[18]}$ This survey examines knowledge, attitudes, and practices concerning the evaluation of GHD in adults and use of GHRT in patients with GHD after pituitary surgery by specialist centers across several primarily Arabian Gulf states.

\section{SUBJECTS AND METHODS}

\section{Design}

A cross-sectional online questionnaire survey of physicians was conducted. The commercial software Survey Monkey (www.surveymonkey.com) was used for the survey

\section{Table I: Survey instrument comprising two parts: Part I. capturing the demographic and professional profiles and Part II. containing the growth hormone therapy (GHT) questionnaire}

\section{Part I. Demographic and professional profiles}

QI. Please start by indicating your eligibility and willingness to participate in the survey: [Options: I am medically qualified and I am willing to participate in the survey, I am NOT medically qualified doctor and I will not participate in the survey, I am medically qualified doctor but I do not wish to take part in this survey.]

Q2. Please indicate your specialty: [Responses:Adult Endocrinology, General Internal Medicine, Primary Care (GP or Family Physician), Other (please specify)].

Q3. Please indicate your current professional grade: [Responses: consultant/attending, specialist].

Q4. Please indicate the type of your clinical practice.[Response options: university or teaching hospital (tertiary level care), district or community (nonteaching) hospital, primarily research-based and teaching-based with limited clinical practice, private practice].

Q5. How many patients with GHD after pituitary surgery do you see per year? [Options: None, I-5, 6-10, II-15, I6-20, >20].

Q6. How many patients with hypopituitarism on GH replacement do you have in you practice currently? [Responses: None, I- 5, 6- I0, II-I5, I6-20, >20].

Part II.The GHD Questionnaire:

QI. Do you believe that GHRT is beneficial in patients with GHD after pituitary surgery?

[Responses:Yes, No].

Q2. Do you replace $\mathrm{GH}$ in patients with GHD after pituitary surgery: [Options:Yes, No]?

Q3. Which patients with GHD are considered for GHRT? [Options:All patients, Symptomatic patients only].

Q4. In a patient with possible hypopituitarism after surgery, the best screening test to assess GH deficiency is: [Options: Morning IGF-I level, GH level in response to insulin tolerance test, Morning GH level and IGF-I, GH level in response to glucagon].

Q5. In a patient with possible hypopituitarism post-surgery, which one of the tests do you usually use to confirm GH deficiency (You may check more than one answer) [Options: Insulin tolerance test, Glucagon stimulation test, Arginine/GHRH,Arginine,Arginine/L-dopa, L-dopa], low IGF-I after pituitary surgery.

Q6. How to diagnose GH deficiency in a patient with a documented deficiency in three pituitary axes? [Options: Serum IGF-I, GHRH-arginine test, ITT] Q7. Do you evaluate the quality of life in patients with GH deficiency prior to and during GH Therapy? Yes - By standard clinical interview? [Options: No, Yes - Using formal "AGHDA" scale, Yes - Using other QoL instruments].

Q8. What are the positive impacts of GH replacement therapy on a patient with GHD after pituitary surgery (You may check more than one answer)? [Options: Improve body composition (increase lean body mass), Promotes a sense of well-being, Improve the quality of life, improve bone density, Reduce cardiovascular risk factors]

Q9.What is the negative impact of GH replacement therapy in GHD after pituitary surgery (You may check more than one answer)? [Responses: glucose intolerance, arthralgia, edema, headache, pain in the extremities, Stiffness, Respiratory tract infection].

QI0. Do patients with GHD after pituitary surgery generally suffer from the side effect of GH therapy? [Options:Yes, No].

QI I.How many patients on GH replacement post- trans-sphenoidal surgery discontinued GH after 6 months of use (no significant benefit): [Options: none, less than $50 \%$, more than $50 \%$, all of them].

Q12.What are the main barriers to GH therapy adherence in adult patients in general? (Please check up to FIVE items only) [Options: being an injection, Inadequate supply, Cost of medication of GH, Lack of symptoms of GHD and apparent ineffectiveness of GHT

Physicians' unawareness, Unclear professional guidelines, Lack of understanding of condition or instructions, Lack of evidence-base for a clear benefit, Social inconvenience and side effects of GHT, Forgetfulness, Preoccupation]. 
between July 2017 and August 2018. Our initial invitation to participate in the survey explained its rationale and objectives. After the initial invitation, six reminders were sent to non- and partial responders. All respondents gave informed electronic consent before they could answer the questionnaire. Ethical approval was granted by the Institutional Review Board of Sheikh Khalifa Medical City, Abu Dhabi, United Arab Emirates (UAE).

\section{Target participants}

Participants were selected from among authors, speakers, and delegates at a series of conferences and educational activities. Due to the kinds of databases used, additional questions were included to ensure the relevance of the respondents' replies to the survey objectives. Only independent practitioners (consultants and senior specialists) were included. In total, 192 doctors responded to the survey, and of those, 131 respondents completed the survey and met participation criteria (endocrinologists or internists with an interest in and practice of endocrinology residing and practicing within the MENA region).

\section{Questionnaire}

The 18-question questionnaire was developed de novo by one author (EA) and revised by the others[Table 1]. The first six questions included the consent and ascertained respondent demographic and professional profiles. The number of the respondent's patients with GHD post-pituitary surgery seen every year and the number of hypopituitarism patients on GH replacement under the respondent's care were also documented. The remaining 12 questions ("The GHRT Questionnaire") included questions based on the key points from the review of the literature targeting the respondent's knowledge of and attitude toward adult GHD management.

\section{Statistical analysis}

Questionnaire responses were collected anonymously. Data were summarized in descriptive statistics. Categorical variables are presented as absolute and relative frequencies (\%). The statistical significance of differences between groups was evaluated with the chi-square test (ANOVA) using an online statistical software package from Social Science Statistics (www.socscistatistics.com).

\section{RESULTS}

\section{Respondent profiles}

Among the 192 responses received, 131 were considered valid. Respondents who did not complete "The GHRT Questionnaire" were excluded. The 131 respondents answered all questions and were analyzed as study subjects. Ninety-nine (76\%) were senior consultants (attending physicians) who practiced primarily in the Arabian Gulf $(84 \%)$ and in tertiary care centers (73\%). Four-fifths of the respondents had seen at least 1 to 5 patients with GHD following pituitary surgery per year. About 59\% of the respondents reported having hypopituitarism patients on GH replacement at the time of the survey. The respondents' educational background and work experience is summarized in Table 2.

\section{Diagnosis and management}

Table 3 outlines respondent attitudes and practices with respect to GHD and GHRT. Seventy-four percent of responding physicians acknowledged the in-principle benefits of GHRT to patients with GHD following pituitary surgery, but only $52 \%$ of these doctors said that they used GHRT. Most (84\%) respondents would consider using GHRT only for symptomatic patients. Forty-four percent of respondents screened patients with serum IGF-1 levels. The insulin tolerance test (ITT) and glucagon stimulation test were the two most common provocative tests used to confirm GHD, and were chosen by $71 \%$ and $40 \%$ of respondents, respectively. However, in diagnosing GHD among patients with documented deficiency in three pituitary axes, $57 \%$ of

\begin{tabular}{|c|c|}
\hline Characteristics and (respondents numbers) & Results \\
\hline \multicolumn{2}{|l|}{ Current professional grade (|3|) } \\
\hline Consultant/attending & $99(76 \%)$ \\
\hline Specialist/fellow & $32(24 \%)$ \\
\hline Resident in training & $0(0 \%)$ \\
\hline \multicolumn{2}{|l|}{ Location of clinical practice (|3|) } \\
\hline Arabian Gulf & II 0 (84\%) \\
\hline Rest of the Middle East & II (8\%) \\
\hline North Africa & $5(4 \%)$ \\
\hline South East Asia & $5(4 \%)$ \\
\hline \multicolumn{2}{|l|}{ Type of clinical practice $(|3|)$} \\
\hline University or teaching hospital (Tertiary level care). & $95(73 \%)$ \\
\hline District or community (nonteaching) hospital. & $16(12 \%)$ \\
\hline $\begin{array}{l}\text { Primarily research-based and teaching-based with limited } \\
\text { clinical practice }\end{array}$ & $2(2 \%)$ \\
\hline Private practice. & $17(13 \%)$ \\
\hline \multicolumn{2}{|l|}{$\begin{array}{l}\text { How many patients with GHD after pituitary surgery do you } \\
\text { see per year? }(|3|)\end{array}$} \\
\hline None & $26(19.8 \%)$ \\
\hline $1-5$ & $69(52.7 \%)$ \\
\hline $6-10$ & $15(11.5 \%)$ \\
\hline $11-15$ & $13(9.9 \%)$ \\
\hline $16-20$ & $2(1.5 \%)$ \\
\hline$>20$ & $6(4.6 \%)$ \\
\hline \multicolumn{2}{|l|}{$\begin{array}{l}\text { How many patients with hypopituitarism on GH replacement } \\
\text { do you have in your practice currently? }(|3|)\end{array}$} \\
\hline None & $54(4 \mid .2 \%)$ \\
\hline $1-5$ & $52(39.7 \%)$ \\
\hline $6-10$ & $12(9.1 \%)$ \\
\hline $11-15$ & $7(5.3 \%)$ \\
\hline $16-12$ & $3(2.3 \%)$ \\
\hline$>20$ & $3(2.3 \%)$ \\
\hline
\end{tabular}




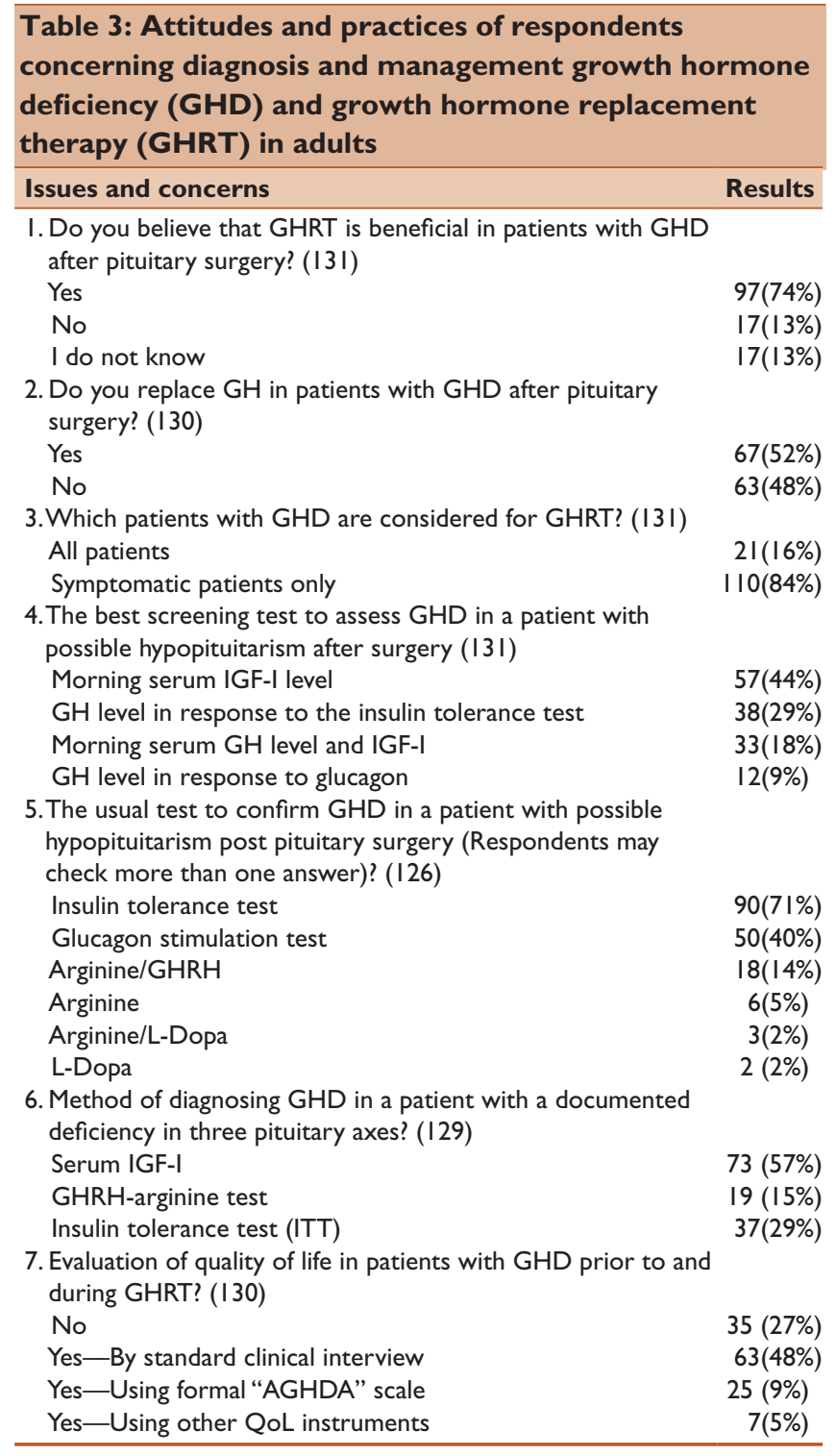

our respondents would consider serum IGF-I levels, 29\% the ITT and 15\% the GHRH-arginine test. Twenty-seven percent of the respondents did not evaluate GHD patient QoL in patients prior to or during GHRT, but $48 \%$ assessed responses in standard clinical interviews and only a minority used a formal AGHDA scale (19\%) or other QoL assessment scales (5\%).

\section{Perceptions of growth hormone replacement} benefits and side effects

Most (85\%) respondents recognized GHRT's positive impact on adult GHD patients, specifically by improving body composition (increased lean body mass), promoting a sense of well-being and enhancing QoL. However, fewer respondents reported that they knew it had a positive impact on augmenting bone density or reducing cardiovascular risk factors [Figure 1A]. GHRT side effects that were well recognized by respondents included glucose intolerance and arthralgia, edema, headache, pain in extremities, stiffness and respiratory tract infections [Figure 1B]. The majority (84\%) of respondents stated that patients with GHD after pituitary surgery generally do not suffer from GH therapy side effects. However, answers to the question of how many respondents discontinue $\mathrm{GH}$ after 6 months due to no perceived significant benefit varied significantly, ranging from none (25.6\%) to less than half (49.6\%), more than half (15.2\%) and all patients (9.6\%). Respondents reported that the main barriers to adult patient GH therapy adherence were that treatment requires injections (67\%). Other barriers cited by $38 \%-61 \%$ of the respondents in descending order are that $\mathrm{GH}$ medication is expensive and in short supply, the patient presents no symptoms of GHD or GHT is apparently ineffective, the physician is unaware of the medication and professional guidelines are unclear. Other less wellrecognized barriers included lack of understanding of the condition or treatment instructions, lack of evidence-based data of clear benefits, social inconvenience, GHRT side effects, forgetfulness, and preoccupation [Figure 1C].

\section{Comparison with Chinese survey}

The principal responses of the respondents from the present survey were compared with those of a recently published Chinese survey. ${ }^{[18]}$ More than half of the Chinese respondents were enrolled in training programs and one in five had no GHD patients under their care. Table 4 summarizes respondent characteristics, diagnostic evaluation of GHD, and GHRT's potential benefits and limitations. There were no major differences in responses except for expense, with Chinese physicians more cost-conscious than their MENA counterparts.

\section{DISCUSSION}

GHD in adults is a relatively rare disease with an average incidence rate of 3.3 per 100,000 per year. ${ }^{[19-23]}$ However, studies have found persistent adult GHD (AGHD) to be common after pituitary surgery. ${ }^{[24]}$ In one study, the overall incidence of AGHD was reported to be $80.2 \%$ as early as three months following such a procedure. ${ }^{[25]}$ The association of AGHD with increased vascular mortality is a major reason for concern and an important factor for initiating GH therapy. ${ }^{[26,27]}$

A lack of GHD symptoms readily recognized by patients, made the treating physician more responsible for assessing GHD status and determining its management. This survey accordingly explored MENA region physician perceptions and practices in terms of GHRT use for AGHD following pituitary surgery. 


\section{A. Acknowledged benefits of GHRT in adults. ( $\mathrm{N}=129)$}

\section{Reduces cardiovascular risk factors}

Improves bone density

Improves quality of life.

Promotes a sense of well-being

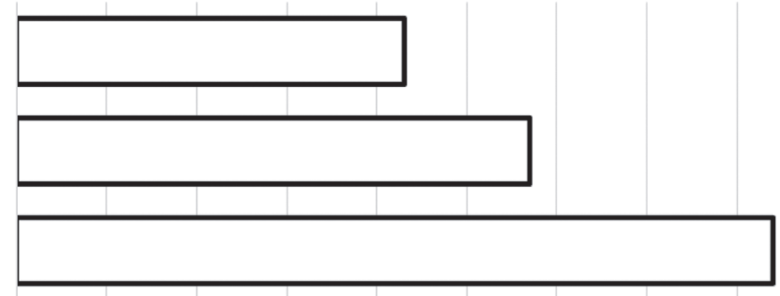

$\begin{array}{llllllllll}0 & 10 & 20 & 30 & 40 & 50 & 60 & 70 & 80 & 90\end{array}$

\section{B. Perceived side effects of GHRT in GHD adults ( $\mathrm{N}=128)$.}

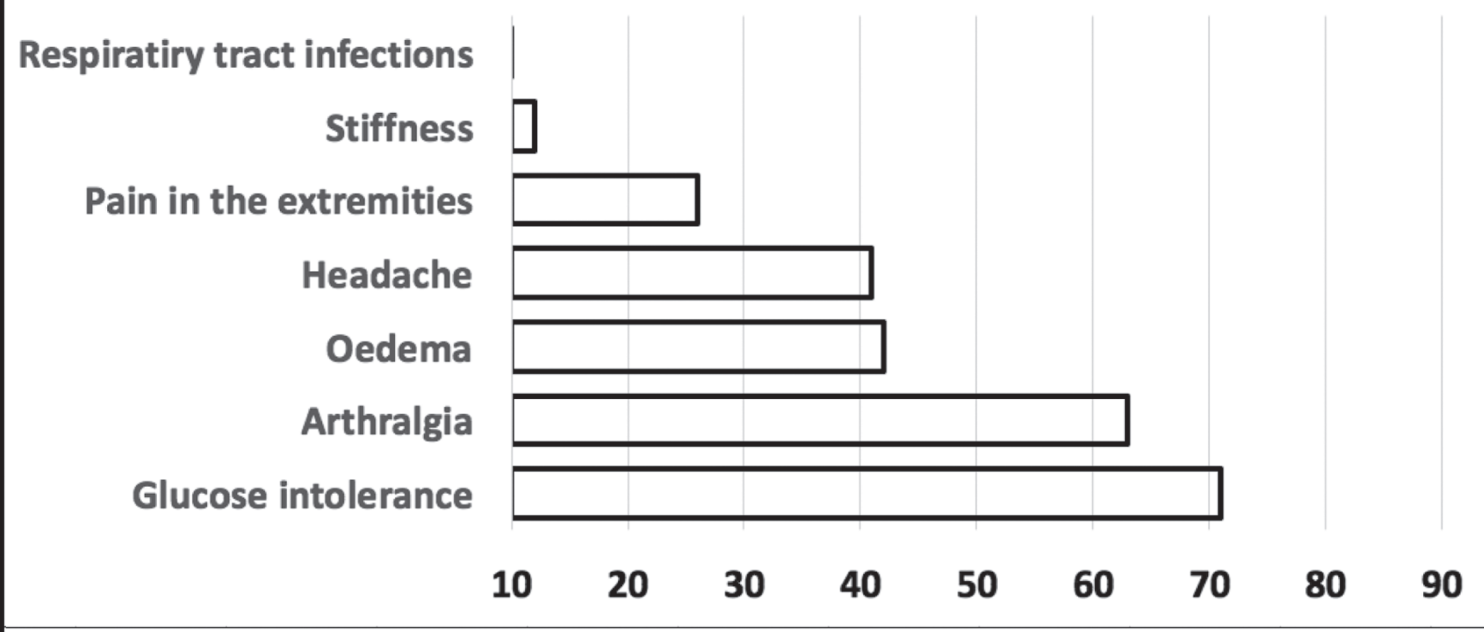

\section{Main barriers to $\mathrm{GHRT}$ adherence $(\mathrm{N}=128)$}

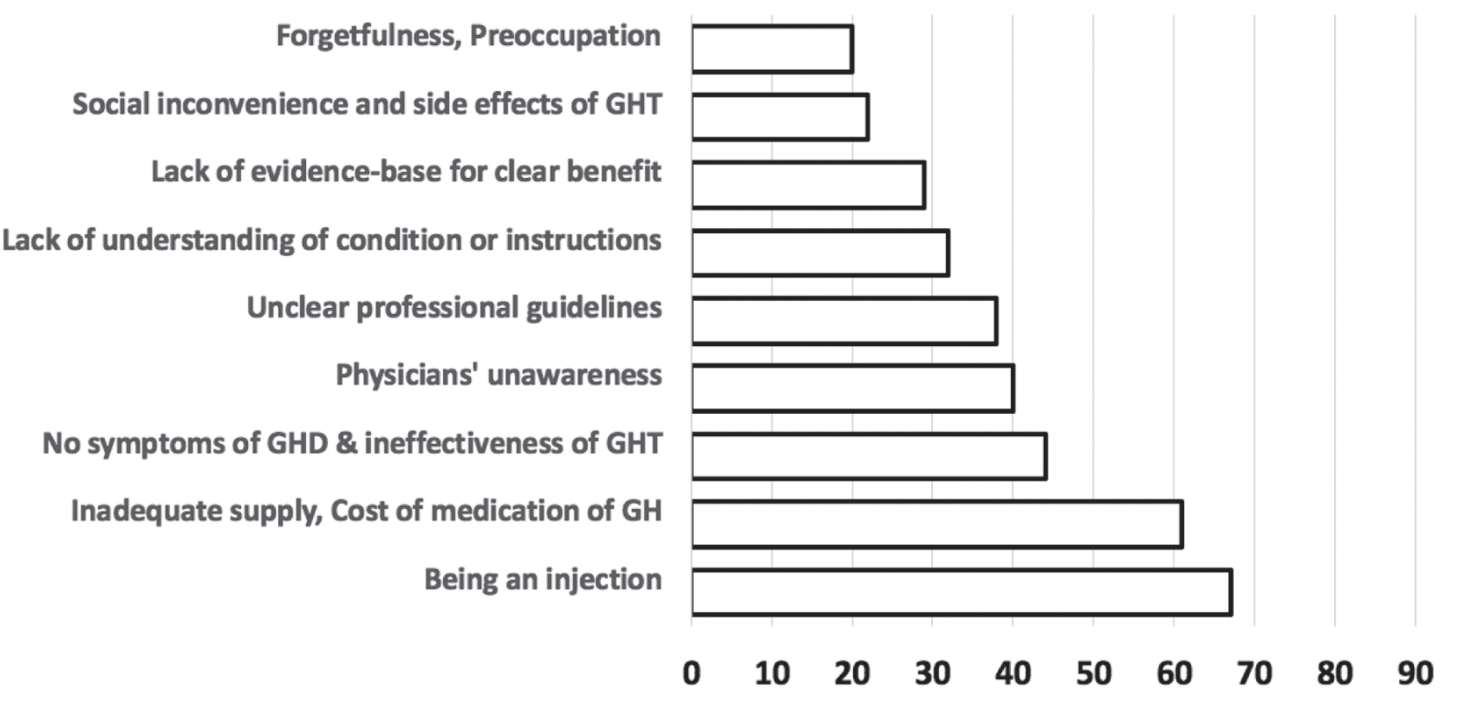

Figure 1: Respondents' perceptions of the benefits (A), side effects (B), and barriers and reasons of discontinuation of GHRT in adults with GHD (C). The $x$-axis is the relative of respondents' mean percentage and the $y$-axis is the various options 


\begin{tabular}{|c|c|c|}
\hline Aspects of the study & This study & Chinese study \\
\hline Number of valid responses & $|3|^{a}$ & 122 \\
\hline \multicolumn{3}{|l|}{ Characteristics of respondents } \\
\hline The site (source) & Mostly Arabian Gulf & Peking UMCH \\
\hline Settings & Regional: Multicenter & Local: Single center \\
\hline \multicolumn{3}{|l|}{ Seniority of respondents } \\
\hline Residents & None & $61 / 118(51.7 \%)$ \\
\hline Senior physicians & $99(76)$ & $57 / 118(48.3 \%)$ \\
\hline Mid-grade (including fellows) & $32(24 \%)$ & Not stated \\
\hline \multicolumn{3}{|l|}{ The workload of GHD (patients/year) ${ }^{b, c}$} \\
\hline None & $26 / 131(20 \%)$ & NA \\
\hline $\mathrm{I}-5$ & $69 / 131$ (53\%) & $92 / 118$ (78\%) \\
\hline $6-10$ & $15 / 131$ (11\%) & $15 / 118(12.7 \%)$ \\
\hline$>10$ & $21 / 131(17 \%)$ & $11 / 118(9.3 \%)$ \\
\hline Acknowledging GHD in adults ${ }^{c}$ & $110 / 129(85 \%)$ & $85 / 118$ (72\%) \\
\hline \multicolumn{3}{|l|}{ Establishing the diagnosis of $\mathrm{GHD}^{\mathrm{c}, \mathrm{d}}$} \\
\hline Serum IGF-I level & $56 / 129(43 \%)$ & $81 / 118$ (68.6\%) \\
\hline Use of IGF-I with multiple hormone deficiencies & $110 / 129(85 \%)$ & $85 / 118(72 \%)$ \\
\hline \multicolumn{3}{|l|}{ Recognized benefits of GHRT in adults ${ }^{c}$} \\
\hline Improvement of Body composition & $110 / 129(85 \%)$ & 85/II8 (72\%) \\
\hline Improvement of QoL & $110 / 129(85 \%)$ & $106 / 118(89.8 \%)$ \\
\hline Reducing metabolic or CV risk factors & $56 / 129(43 \%)$ & $81 / 118(68.6 \%)$ \\
\hline \multicolumn{3}{|l|}{ Concerns on GHRT and barriers of usage } \\
\hline Adverse effect on glucose level $\left.\right|^{\mathrm{c}, \mathrm{d}}$ & $91 / 128(66 \%)$ & 78/1 I8 (71\%) \\
\hline Compliance $^{\mathrm{c}, \mathrm{f}}$ & $86 / 129(67 \%)$ & $70 / 118(59.3 \%)$ \\
\hline Cost $^{\mathrm{g}}$ & $79 / 129(61 \%)$ & $109 / 118(92.3 \%)$ \\
\hline \multicolumn{3}{|c|}{$\begin{array}{l}{ }^{2} \text { Total number of valid responses in this study was I3I; however, not all questions were answered so adjustments were made for individual questions and used percentage } \\
\text { expression for comparison between studies }\end{array}$} \\
\hline \multicolumn{3}{|c|}{ 'Cutoff points minimally approximated } \\
\hline \multicolumn{3}{|c|}{ ¿Not significant } \\
\hline \multicolumn{3}{|c|}{ 'Our survey, IGF-I was used by $44 \%$ as a screening test, Chinese study:"as a diagnostic test.” $22.8 \%$ will use IGF-I, $56.8 \%$ will use provocative test (GHRH-arginine and ITT) } \\
\hline \multicolumn{3}{|c|}{ eGlucose intolerance in this study, worries about hyperglycemia in the Chinese study } \\
\hline \multicolumn{3}{|c|}{ 'Extrapolated from the respondent's selection of "being an injection" to the question of the main barriers to GH therapy } \\
\hline $8 P<0.0001$ & & \\
\hline
\end{tabular}

AGHD symptoms and signs are nonspecific and the diagnosis is primarily based on biochemical assessment. ${ }^{[28]}$ In our survey, IGF-1 was the GHD screening test used by most respondents, followed by measuring $\mathrm{GH}$ levels in response to ITT (the dynamic gold standard diagnostic test). ${ }^{[29,30]}$ The two most common provocative tests used by our respondents for GHD confirmation were ITT and glucagon stimulation, whereas a similar Chinese survey reported greater use of ITT and GHRH/arginine for diagnosis. ${ }^{[18]}$ Provocative testing for diagnosis corresponds with AACE guidelines which suggest conducting a stimulation test in the absence of documented multiple pituitary hormone deficiencies. ${ }^{[29]}$

For confirmation of AGHD in patients with a documented deficiency in three pituitary axes, our findings are similar to Yang et al. ${ }^{[18]}$ who also showed that most respondents preferred to consider IGF-1 levels in patients with multiple pituitary hormone deficiencies. Although existing guidelines recommend the IGF-1 test for such patients, they make provocative tests as optional-explaining the $43 \%$ increase in their use by our respondents. The decision to perform biochemical tests was, in other words, subjective and probably done with feasibility or availability of assays at hospital laboratories.
$\mathrm{GH}$ treatment has been shown to improve both traditional and emerging cardiovascular risk factors and markers and therefore offer CV protection, although evidence is limited. ${ }^{[31]}$ Current guidelines suggest patients with AGHD will benefit from GH replacement. ${ }^{[7,29,32]}$ Yet there is a lack of general consensus among attending physicians in determining which patients will benefit from treatment due to inadequate evidence. ${ }^{[33]}$ Our findings agreed with Yang et al. ${ }^{[18]}$ who showed that most of their respondents acknowledged the benefits of GH replacement therapy. The majority were well aware of the positive impact of GHRT on body composition (increased lean body mass), sense of well-being, improved QoL and better bone density. ${ }^{[22,29,34]}$

Physician recommendations differed on whether or not to initiate GH replacement. Although most concurred in treating AGHD following pituitary surgery, the decision to initiate therapy was strongly influenced by their patient's willingness to adhere to it. Our survey also shows that the most important factor in non-adherence was the need for a daily injection. The second reason was inconsistent supply due to the relatively high cost of GH. A physician's decision to stop treatment was usually based on an absence 
of AGHD symptoms and apparent ineffectiveness of GHRT. A small number of physicians did not begin the treatment due to their apparent lack of familiarity with the therapy and unclear professional guidelines. Other barriers included lack of understanding of the condition or instructions, lack of evidence that GHRT provides clear benefits, social inconvenience, and side effects-such as forgetfulness and preoccupation [Figure 1C]. These selection choices indicate that physician decisions were based on patient compliance and personal preferences rather than recommended guidelines. Their choices were also dictated by their perceptions of what would be most acceptable to their patients and availability of GH injections in their health centers or hospitals. The major adverse effect of the treatment (development of glucose intolerance, as described in a previous study ${ }^{[35]}$ ) was also considered by many of the respondents.

The majority of our respondents saw few post-pituitary surgery patients in their clinical practice and even less who had begun GHT. A greater number of these respondents preferred treating their patients with GHRT only if they were found to be symptomatic or had symptoms of active disease. That decision is in line with guidelines that GHRT should be prescribed only to patients with clinical signs suggesting AGHD and biochemically proven evidence of AGHD as it offers significant clinical benefits in terms of body composition, exercise capacity, skeletal integrity and QoL. ${ }^{[7,36]}$

AGHD clinical findings, which pertain to nonspecific symptoms, are usually of little diagnostic value. ${ }^{[22]} \mathrm{An}$ absence of characteristic clinical signs makes diagnosis dependent on biochemical tests to confirm the presence of AGHD. Random GH measurement is usually unreliable due to its pulsatile secretion. For this reason, measuring IGF-1 in conjunction with $\mathrm{GH}$ is preferable, to improve the likelihood of a diagnosis. ${ }^{[19]}$ AACE guidelines suggested against use of stimulation testing if there are documented multiple pituitary hormone deficiencies or using one stimulation test if otherwise not known. ${ }^{[29]}$ Among provocative tests, ITT remains the gold standard dynamic test for diagnosing GHD. ${ }^{[29,30]}$

GH replacement therapy benefits were acknowledged in our study by most respondents, who agreed about the positive impact of its use on body composition (increased lean body mass), sense of well-being, plus improved QoL, bone density, diastolic blood pressure, total cholesterol and LDL, in line with the findings from previous studies. ${ }^{[22,29,34]}$

This study is the second such survey worldwide and the first from an emerging region with heavy public funding of health care offering approved GHRT access for potential patients. Our survey respondents were more senior than those of the Chinese study, which included many junior trainees. However, results are limited by the kind of survey, small sample, and the region's diverse representation. Many physicians may not appreciate the importance of mapping the region's practices and their comparison with the global situation. Also, the study reflects physician perceptions and self-reported practices rather than assessing quality of clinical practice. Finally, one in five respondents did not have any GHD patients under their care at the time of the survey, suggesting that centralization is probably very important, where possible.

In conclusion, this survey considered physician knowledge, attitudes, and practices in recognizing, initiating, and treating GHD with GHRT in adults following pituitary surgery. Most of our respondents were senior physicians who acknowledged the benefits of GHRT. Over 50\% prescribed GH in their daily practice. The survey also helped identify several barriers in initiating and adhering to GHRT that might contribute to low prescription rates. MENA region guidelines must be developed to help address/tackle these issues and assist physicians in understanding and treating this condition.

\section{Ethical policy and institutional review board statement}

Ethical approval was granted from Institutional Review Board of Sheikh Khalifa Medical City, Abu Dhabi, United Arab Emirates (UAE). All respondents provided informed consent electronically before they were able to proceed to the survey questions.

\section{Financial support and sponsorship}

Nil.

\section{Conflicts of interest}

There are no conflicts of interest.

\section{REFERENCES}

1. Cuneo RC, Salomon F, McGauley GA, Sönksen PH. The growth hormone deficiency syndrome in adults. Clin Endocrinol (Oxf) 1992;37:387-97.

2. Rosén T, Bengtsson BÅ. Premature mortality due to cardiovascular disease in hypopituitarism. Lancet 1990;336:285-8.

3. Beshyah SA, Johnston DG. Cardiovascular disease and risk factors in adults with hypopituitarism. Clin Endocrinol (Oxf) 1999;50:1-15.

4. Bates AS. The effect of hypopituitarism on life expectancy. J Clin Endocrinol Metab 1996;81:1169-72.

5. Uzunova I, Kirilov G, Zacharieva S, Shinkov A, Borissova AM, Kalinov K. Individual risk factors of the metabolic syndrome in adult patients with growth hormone deficiency - A cross-sectional case-control study. Exp Clin Endocrinol Diabetes 2014;123:39-43. 
6. Ahmad AM, Hopkins MT, Thomas J, Ibrahim H, Fraser WD, Vora JP. Body composition and quality of life in adults with growth hormone deficiency; effects of low-dose growth hormone replacement. Clin Endocrinol (Oxf) 2001;54:709-17.

7. Molitch ME, Clemmons DR, Malozowski S, Merriam GR, Vance ML; Endocrine Society. Evaluation and treatment of adult growth hormone deficiency: An endocrine society clinical practice guideline. J Clin Endocrinol Metab 2011;96:1587-609.

8. Schneider HJ, Aimaretti G, Kreitschmann-Andermahr I, Stalla GK, Ghigo E. Hypopituitarism. Lancet 2007;369:1461-70.

9. Jørgensen JOL, Thuesen L, Ingemann-Hansen T, Pedersen SA, Jørgensen I, Skakkebaek NE, et al. Beneficial effects of growth hormone treatment in GH-deficient adults. The Lancet 1989;333:1221-5.

10. de Boer H, Blok GJ, Van der Veen EA. Clinical aspects of growth hormone deficiency in adults. Endocr Rev 1995;16:63-86.

11. Carroll PV, Christ ER, Bengtsson BÅ, Carlsson L, Christiansen JS, Clemmons D, et al. Growth hormone deficiency in adulthood and the effects of growth hormone replacement: A review. J Clin Endocrinol Metabol 1998;83:382-95.

12. Russell-Jones DL, Watts GF, Weissberger A, Naoumova R, Myers J, Thompson GR, et al. The effect of growth hormone replacement on serum lipids, lipoproteins, apolipoproteins and cholesterol precursors in adult growth hormone deficient patients. Clin Endocrinol (Oxf) 1994;41:345-50.

13. Carroll PV, Littlewood R, Weissberger AJ, Bogalho P, McGauley G, Sönksen PH, et al. The effects of two doses of replacement growth hormone on the biochemical, body composition and psychological profiles of growth hormone-deficient adults. Eur J Endocrinol 1997;137:146-53.

14. Hoffman AR, Kuntze JE, Baptista J, Baum HB, Baumann GP, Biller BM, et al. Growth hormone $(\mathrm{GH})$ replacement therapy in adult-onset gh deficiency: Effects on body composition in men and women in a double-blind, randomized, placebo-controlled trial. J Clin Endocrinol Metab 2004;89:2048-56.

15. Hatrick AG, Boghalo P, Bingham JB, Ayres AB, Sonksen PH, RussellJones DL. Does GH replacement therapy in adult GH-deficient patients result in recurrence or increase in size of pituitary tumours? Eur J Endocrinol 2002;146:807-11.

16. Arnold JR, Arnold DF, Marland A, Karavitaki N, Wass JA. GH replacement in patients with non-functioning pituitary adenoma (NFA) treated solely by surgery is not associated with increased risk of tumour recurrence. Clin Endocrinol (Oxf) 2009;70:435-8.

17. Frajese G. Hypothalamo-pituitary surveillance imaging in hypopituitary patients receiving long-term GH replacement therapy.J Clin Endocrinol Metab 2001;86:5172-5.

18. Yang HB, Zhang MQ, Pan H, Zhu HJ. Management of adult growth hormone deficiency at peking union medical college hospital: A survey among physicians. Chin Med Sci J 2016;31:168-72.

19. Kargi AY, Merriam GR. Diagnosis and treatment of growth hormone deficiency in adults. Nat Rev Endocrinol 2013;9:335-45.

20. Abdi L, Sahnoun-Fathallah M, Morange I, Albarel F, Castinetti F, Giorgi R, et al. A monocentric experience of growth hormone replacement therapy in adult patients. Ann Endocrinol (Paris) 2014;75:176-83.

21. Mathioudakis N, Salvatori R. Adult-onset growth hormone deficiency: Causes, complications and treatment options. Curr Opin Endocrinol Diabetes Obes 2008;15:352-8.

22. Al-Shoumer KA, Gray R, Anyaoku V, Hughes C, Beshyah S, Richmond W, et al. Effects of four years' treatment with biosynthetic human growth hormone $(\mathrm{GH})$ on glucose homeostasis, insulin secretion and lipid metabolism in GH-deficient adults. Clin Endocrinol (Oxf) 1998;48:795802.

23. Reed ML, Merriam GR, Kargi AY. Adult growth hormone deficiency benefits, side effects, and risks of growth hormone replacement. Front Endocrinol (Lausanne) 2013;4:64.

24. Cook DM, Yuen KC, Biller BM, Kemp SF, Vance ML; American Association of Clinical Endocrinologists. American association of clinical endocrinologists medical guidelines for clinical practice for growth hormone use in growth hormone-deficient adults and transition patients - 2009 update. Endocr Pract 2009;15:1-29.

25. Yuen KC, Tritos NA, Samson SL, Hoffman AR, Katznelson L. American association of clinical endocrinologists and American college of endocrinology disease state clinical review: Update on growth hormone stimulation testing and proposed revised cut-point for the glucagon stimulation test in the diagnosis of adult growth hormone deficiency. Endocr Pract 2016;22:1235-44.

26. Pfeifer M, Verhovec R, Zizek B, Prezelj J, Poredos P, Clayton RN. Growth hormone $(\mathrm{GH})$ treatment reverses early atherosclerotic changes in $\mathrm{GH}-$ deficient adults. J Clin Endocrinol Metab 1999;84:453-7.

27. Erfurth EM, Bülow B, Eskilsson J, Hagmar L. High incidence of cardiovascular disease and increased prevalence of cardiovascular risk factors in women with hypopituitarism not receiving growth hormone treatment: Preliminary results. Growth Horm IGF Res 1999;9:21-4.

28. Molitch ME, Clemmons DR, Malozowski S, Merriam GR, Shalet SM, Vance ML, et al.; Endocrine Society's Clinical Guidelines Subcommittee. Evaluation and treatment of adult growth hormone deficiency: An endocrine society clinical practice guideline. J Clin Endocrinol Metab 2006;91:1621-34.

29. Allen DB, Backeljauw P, Bidlingmaier M, Biller BM, Boguszewski M, Burman P, et al. GH safety workshop position paper: A critical appraisal of recombinant human GH therapy in children and adults. Eur J Endocrinol 2016;174:P1-9.

30. Maison P, Griffin S, Nicoue-Beglah M, Haddad N, Balkau B, Chanson P. Impact of Growth Hormone $(\mathrm{GH})$ treatment on cardiovascular risk factors in GH-deficient adults: A meta-analysis of blinded, randomized, placebo-controlled trials. J Clin Endocrinol Metabol 2004;89:2192-9.

31. Møller N, Jørgensen JO. Effects of growth hormone on glucose, lipid, and protein metabolism in human subjects. Endocr Rev 2009;30:152-77.

32. Roelfsema F, Veldhuis JD. Growth hormone dynamics in healthy adults are related to age and sex and strongly dependent on body mass index. Neuroendocrinology 2016;103:335-44.

33. Laursen T, Gravholt CH, Heickendorff L, Drustrup J, Kappelgaard AM, Jørgensen JO, et al. Long-term effects of continuous subcutaneous infusion versus daily subcutaneous injections of growth hormone $(\mathrm{GH})$ on the insulin-like growth factor system, insulin sensitivity, body composition, and bone and lipoprotein metabolism in GH-deficient adults. J Clin Endocrinol Metab 2001;86:1222-8.

34. Høybye C, Cohen P, Hoffman AR, Ross R, Biller BM, Christiansen JS; Growth Hormone Research Society. Status of long-acting-growth hormone preparations-2015. Growth Horm IGF Res 2015;25:201-6.

35. Reiter EO, Attie KM, Moshang TJr, Silverman BL, Kemp SF, Neuwirth RB, et al.; Genentech, Inc.-Alkermes, Inc. Collaborative Study Group. A multicenter study of the efficacy and safety of sustained release $\mathrm{GH}$ in the treatment of naive pediatric patients with GH deficiency. J Clin Endocrinol Metab 2001;86:4700-6.

36. Gazzaruso C, Gola M, Karamouzis I, Giubbini R, Giustina A. Cardiovascular risk in adult patients with growth hormone $(\mathrm{GH})$ deficiency and following substitution with $\mathrm{GH}$-an update. J Clin Endocrinol Metab 2014;99:18-29. 